\title{
Opinion on Complementary and Alternative Precision Medicine: An Integrated Framework
}

\author{
Sushing Chen* \\ University of Florida, USA
}

Submission: May 03, 2017; Published: June 13, 2017

*Corresponding author: Sushing Chen, University of Florida, USA, Email: suchen@ufl.edu

\section{Opinion}

As the hallmark of modern science and technology of the $21^{\text {st }}$ Century, Precision Medicine (PM) is an initiative announced on January 15, 2015 by President Obama for NIH research programs. It exploits big data, computation and genomics for personalized medicine.

Complementary and Alternative Medicine (CAM) covers a wide variety of diagnosis and therapeutics, using mostly herbal drugs and natural health products. Can these two disparate concepts of CAM and PM (Precision Medicine) be integrated into a single framework? Can we make progress significantly on CAM in the current era of precision or personalized medicine? My opinion is affirmative, described as follows!
In our research [1-3], we have developed diagnostic and therapeutic methods using gene expression profiles. Basically, a data mining approach to select essential biomarkers, which detects patients vs. normal controls. This method can be extended to NGS approach (i.e., SNP signatures). This represents a modern diagnosis technology. From those disease causing gene biomarkers, we can find the protein targets, which are used to discover drugs or therapeutics. The gene biomarkers diagnosed provides personalized disease signatures of a patient, thus, the drugs or therapeutics designed accordingly is the personalized treatment of that patient. All things are at the molecular level, precisely quantified, and easily computable.

\section{Combinatorial Drug Design}

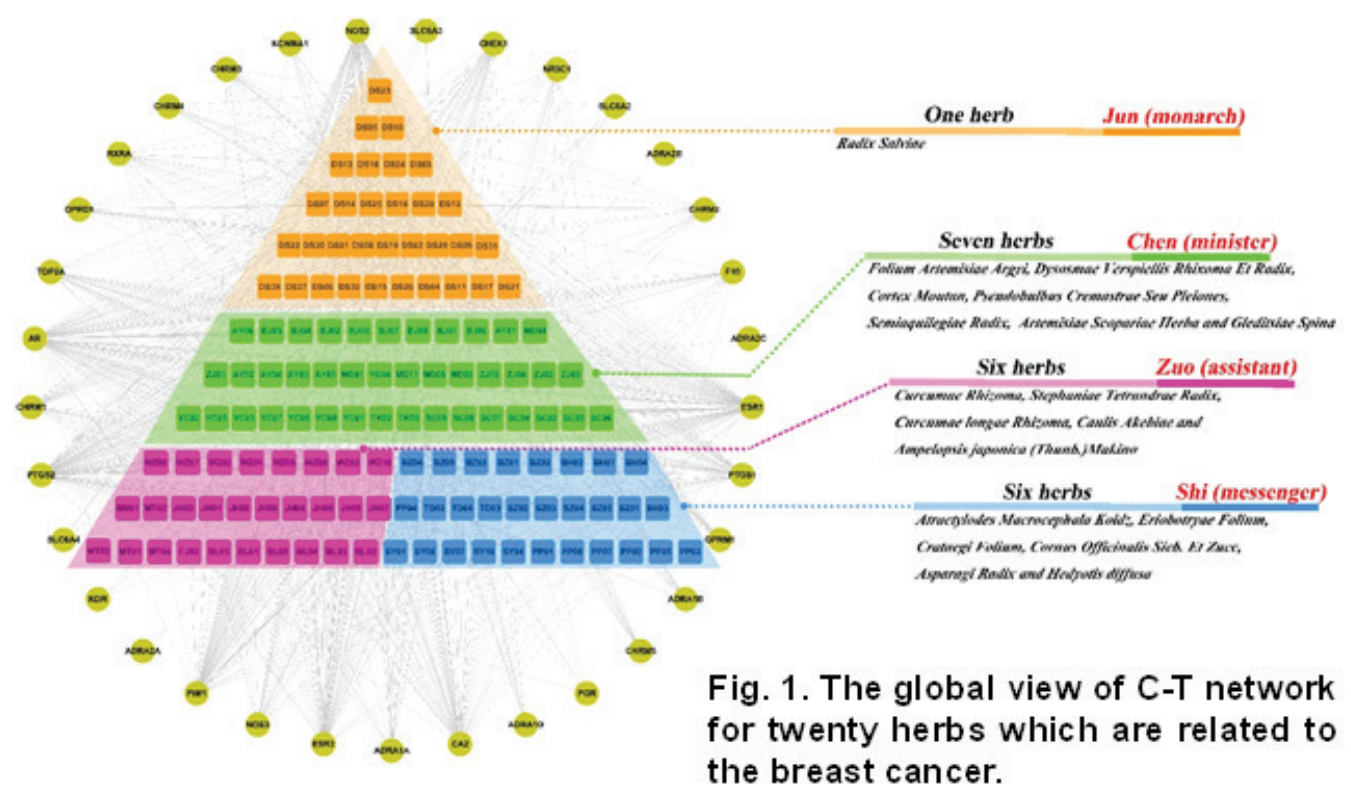

Figure 1: Combinatorial drugs by ranking compounds according to their functionalities. 
At a NCI CAM Workshop in May 2016, for herbal drugs and natural health products, we have presented the concept of Systems Pharmacology (SP) as a computational platform rapidly finding bioactive compouds, associated targets, and relevant pathways. The main idea is QSAR (Quantitative StructureActivity Relationship) modeling, with large databases. The result is usually summarized in various networks: $\mathrm{H}-\mathrm{C}$ networks (HerbCompound), C-T networks (Compound-Target), and T-P networks (Target-Pathway). In [4], we have presented a case study of Breast cancer herbs and its various networks. This methodology is valid for other cancers and diseases (we are in the process of publishing them). Since the results of Systems Pharmacology is precisely quantitatively represented (Figure 1) we may integrate them into the framework of precision medicine described in the previous paragraph. However, herbal drugs and natural health products have significant differences with conventional drugs. The former are multi-compounds and multi-targets, while the latter are single-compound and single target mainly. In recent years, researchers are reporting results about the multiplicity of targets for a single compound, which is usually the goal of patents by the pharmaceutical industry. In contrast, herbs and natural products are not patentable. Indeed, this is a gray area of healthcare with a large market value. This is a gap, not currently addressed.

\section{T-C, P-T networks}

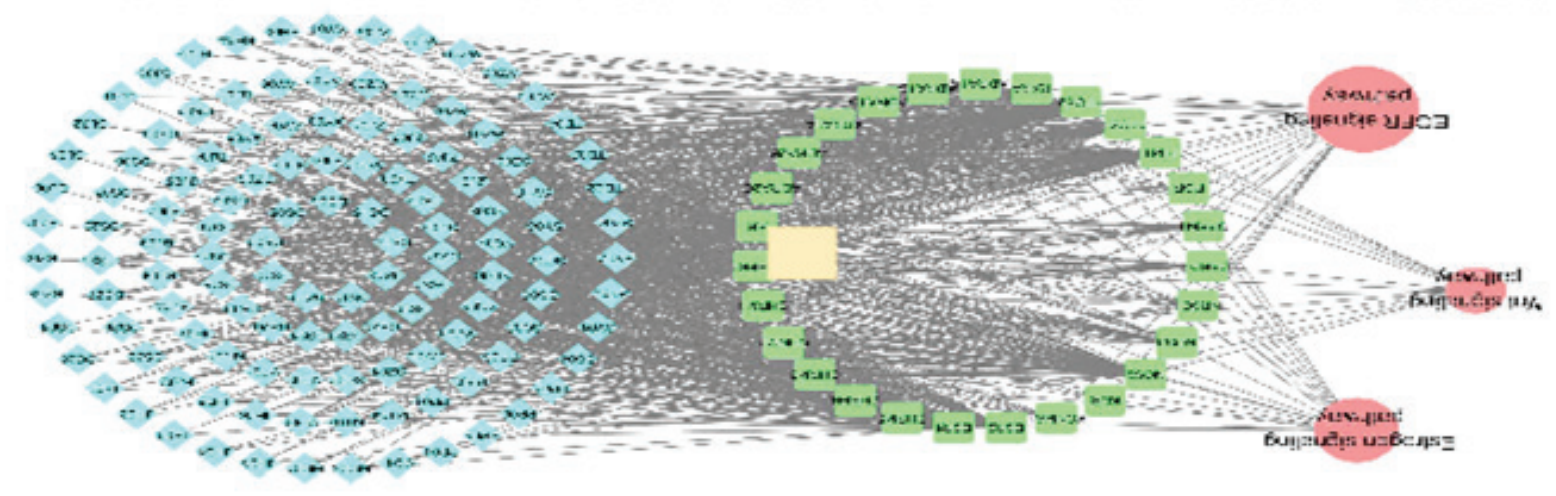

Figure 2: T-C, P-T networks.

Our opinion contributes an important step for improving this situation. That is, herbal drugs and natural health products are delivered to human bodies in the form of chemical compounds, no longer as medicinal soup in TCM (Traditional Chinese Medicine) or natural product extracts. In chemical compounds, known chemical structures can be quantified precisely and delivered into human bodies correctly. Furthermore, we define the new concept of combinatorial drug design by intelligently combining multiple compounds into new combinatorial drugs (Figure 2). For examples, breast cancer has 4 main subtypes, we may design at least 4 different breast cancer personalized therapeutics for individual patients. drugs based on their different sets of biomarkers $[5,6]$.

In conclusion, the above description is not pure speculation, but a practical account of what can be accomplished in the $21^{\text {st }}$ Century. CAM, being complementary and alternative, must follow the main stream trend of medicine and healthcare. Most importantly, the gray area of herbal drugs and natural health products should be regulated by the FDA as legitimate healthcare products, so that rigorous research and study of them can be performed by Systems Pharmacology, Pharmakinetics,
Pharmadynamics and clinical trials. Eventually, our goal should be the benefits of all patients with prevention of diseases. We hope that Precision Medicine will lead to Personalized Medicine and Preventive Medicine-3P Medicine!

\section{References}

1. Hsu WC, Denq C, Chen SS (2013) A diagnostic methodology for Alzheimer's disease. J Clin Bioinforma 3(1): 9.

2. Hsu WC, Liu CC, Chang F, Chen SS (2012) Cancer classification: Mutual information, target network and strategies of therapy, J Clin Bioinforma 2(1): 16.

3. Hsu W, Liu CC, Fu C, Chen SS (2013) Selecting Genes for Cancer Classification Using SVM: An Adaptive Multiple Features Scheme. International Journal Of Intelligent Systems 28(12): 1196-1213.

4. Li Y, Wang J, Lin F, Yang Y, Chen SS (2017) A Methodology for Cancer Therapeutics by Systems Pharmacology-Based Analysis: A Case Study on Breast Cancer-Related Traditional Chinese Medicines, PLoS ONE 12(1): e0169363.

5. Zhang J, Li Y, Chen SS, Zhang L, Wang J, et al. (2015) Systems Pharmacology Dissection of the Anti-Inflammatory Mechanism for the Medicinal Herb Folium Eriobotryae. Int J Mol Sci 16(2): 2913-2941.

6. Li Y, Zhang J, Zhang L, Chen X, Pan Y, et al. (2015) Systems pharmacology to decipher the combinational anti-migraine effects of Tianshu formula. J Ethnopharmacol 174: 45-56. 
This work is licensed under Creative Commons Attribution 4.0 Licens

DOI:10.19080/JCMAH.2017.02.555594
Your next submission with Juniper Publishers

will reach you the below assets

- Quality Editorial service

- Swift Peer Review

- Reprints availability

- E-prints Service

- Manuscript Podcast for convenient understanding

- Global attainment for your research

- Manuscript accessibility in different formats

( Pdf, E-pub, Full Text, Audio)

- Unceasing customer service

Track the below URL for one-step submission https://juniperpublishers.com/online-submission.php 